\title{
Gait Characteristic in a Stroke Patient with an Intact Corticospinal Tract and Corticoreticular Pathway: A Case Study
}

\author{
Sang Seok Yeo, In Hee Cho \\ Department of Physical Therapy, College of Health Sciences, Dankook University, Cheonan, Korea
}

Purpose: The prefrontal lobe, supplementary motor area, cerebellum, and basal ganglia are activated during gait. In addition, gait is controlled by nerves, such as the corticospinal tract (CST) and corticoreticular pathway (CRP). In this study, the presence of an injury to the CST and CRP was identified by diffusion tensor imaging and the characteristics of the gait pattern were investigated according to inferior cerebral artery infarction.

Methods: One patient and six control subjects of a similar age participated. A 69-year-old female patient had an injury to the left basal ganglia, insular gyrus, corona radiata, dorsolateral prefrontal cortex, and postcentral gyrus due to an inferior cerebral artery infarction. Diffusion tensor imaging (DTI) data was acquired 4 weeks after the stroke. The kinematic and spatio-temporal parameters of gait were collected using a three-dimensional gait analysis system.

Results: On 4 weeks DTI, the CST and CRP in the affected hemisphere did not show injury to the affected and unaffected hemisphere. Gait analysis showed that the cadence of spatio-temporal parameter was decreased significantly in the patient. The angle of the knee joint was decreased significantly in the affected and unaffected sides compared to the control group.

Conclusion: The results of diffusion tensor imaging showed that although the patient was evaluated to be capable of an independent gait, the quality and quantity of gait might be reduced. This study could help better understand the gait ability analysis of stroke patients and the abnormal gait pattern of patients with a brain injury.

Keywords: Corticospinal tract, Corticoreticular pathway, Gait analysis, Diffusion tensor imaging

\section{서 론}

보행은 고위중추의 많은 영역의 활성을 통해 복잡하게 유지된다.1-4 보행의 경우 주로 이마앞엽(prefrontal lobe)과 보조운동영역(supplementary motor area) 활성 및 소뇌와 기저핵 등 다양한 영역들을 통해 수행된다.1,4-6 또한, 겉질척수로(corticospinal tact), 겉질그물체로(corticoreticular pathway) 등이 보행을 조절하는 신경으로 작용한다. ${ }^{78}$ 특 히, 겉질척수로는 전반적인 보행기능과 발목관절의 조절에 중요한 역 할을 하는 것으로 알려져 있으며, 겉질그물체로는 전운동영역 (premotor cortex)에서 시작되어 자동적인 보행 기능과 더불어 기능적 보 행의 조절에도 관여하는 것으로 알려져 있다. ${ }^{78}$ 따라서, 이전 연구들 은 뇌의 일부영역이나 신경의 손상 시 각각이 담당하는 역할에 영향 을 미치며, 그 외에 복합적으로 보행 및 균형 또한 영향을 받는다고 보고하였다.9.10
과거에 보행에 관련하여 뇌 기능 중심으로 연구 진행이 어려웠으 나, 최근에는 뇌의 상태를 확인하기 위해 신경 촬영 기법(neuroimaging)이 사용되고 있다. 신경 촬영 기법은 특정한 뇌의 영역 활성을 확 인하거나 비교하기 위한 목적으로 사용된다. 다양한 종류의 관련기 술이 존재하며," 대표적으로 양전자 단층촬영(positron emission tomography), 기능적 자기공명영상(functional magnetic resonance imaging, fMRI), 확산텐서영상(diffusion tensor imaging), 기능적근적외선 분광법(near infrared spectroscopy) 등이 있다." 신경 가소성에 대한 이 해가 높아지면서 다양한 신경 촬영 기법을 통해 뇌 손상 이후 뇌 활 성 및 신경에 관한 연구가 진행되고 있다.12 이전 연구들은 신경 촬영 기법을 이용하여 뇌 가소성을 통한 보행 및 균형의 회복정도를 기록 하였다. ${ }^{78}$ Agosta 등 ${ }^{13}$ 은 움츠린 보행(frozen gait) 양상을 보이는 파킨슨 환자들에게 중재 후 보행 능력과 균형이 증가했음을 보고하였고 이 를 토대로 $\mathrm{fMRI}$ 를 이용하여 확인한 결과 뇌의 활성이 증가한다고 기
Received Mar 21, 2018 Revised Apr 18, 2018

Accepted April 23, 2018

Corresponding author In Hee Cho

E-mail suee43@hanmail.net
Copylight (C) 2018 The Korea Society of Physical Therapy

This is an Open Access article distribute under the terms of the Creative Commons Attribution Non-commercial License (Http:// creativecommons.org/license/by-nc/4.o.) which permits unrestricted non-commercial use, distribution, and reproduction in any medium, provided the original work is properly cited. 
록했다. You 등은 만성 뇌졸중 환자를 대상으로 중재 전과 후의 $\mathrm{fMRI}$ 검사를 시행했을 때 전보다 후에서 일차감각운동겉질(primary sensorimotor cortex)이 더 활성되었으며 이는 보행 회복에 영향을 미 쳤을 것이라고 보고하였다.

뇌졸중 환자들의 $80 \%$ 는 재활 후 일상생활에 문제가 되지 않을 정 도의 보행 회복은 되지만, 나머지는 비대칭성, 발 처짐 등의 양상으로 보행에 문제가 발생하며 보행 속도가 느려지거나 지구력에 제한이 발 생한다.9,14 뇌졸중 뿐만 아니라 파킨슨 병과 같은 뇌 손상 환자들 또한 움츠린 보행 같은 속도가 느려지거나 정상적이지 않은 보행 양상을 나타낸다. ${ }^{13,15}$ 따라서, 보행분석은 신경학적 장애를 가지고 있는 환자 들의 운동조절과 뇌기능 사이 관계를 연구하는 데 가장 효과적인 도 구로 사용된다.16-18

따라서, 본 연구에서는 아래대뇌동맥 경색에 의한 겉질과 겉질 밑 영역에 손상이 있는 한 명의 환자를 대상으로 겉질척수로와 겉질그 물체로의 손상 유무를 확산텐서영상 기법으로 평가하고 그에 따른 보행기능의 양상을 보행분석을 통해 평가하고자 한다.

\section{연구 방법}

\section{1. 연구 대상자}

만성 뇌졸중 환자 1 명과 비슷한 연령대의 신경학적 질병이 없는 6 명 의 대조군(남: 2 명, 여: 4명, 평균나이: 63.3세 [61-68세])이 본 연구에 참 여하였다. 모든 대상자들은 연구 동의서에 서명을 했으며, 본 연구의 과정은 임상연구 심의 위원회로부터 승인 받았다.

69세의 여자 환자로 대학병원 신경과에서 왼쪽 아래대뇌동맥(inferior cerebral artery) 폐색으로 왼쪽 기저핵(basal ganglia), 섬이랑(insular gyrus), 대뇌부챗살(corona radiate), 뒤가쪽이마앞겉질(dorsolateral prefrontal cortex), 중심뒤이랑(postcentral gyrus)에 손상이 있는 것으 로 진단받았다(Figure 1A). 발병 초기에는 상.하지의 도수근력검사 결과 1 등급(trace grade) 정도로 심각한 근력저하가 관찰되었으며, 앉 기 균형과 서기 균형에서도 혼자서 균형을 유지하는 데 어려움이 관 찰되었다. 발병 4 주 후 평가에서는 상지와 하지의 근력검사에서 전반 적으로 3 등급(fair grade)의 결과를 보였으며, 기능적 보행지수(func-
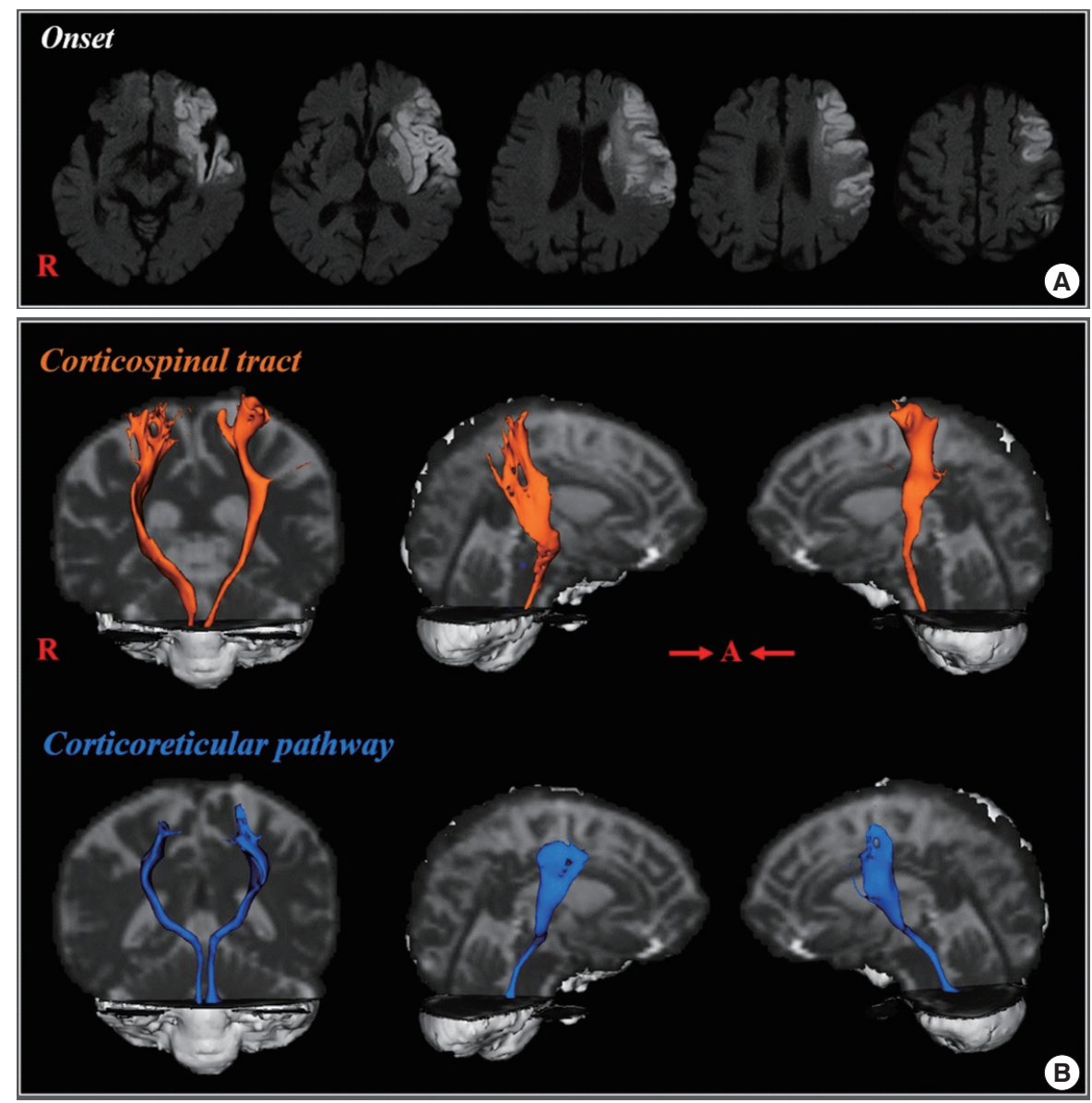

Figure 1. (A) Brain MRI on at stroke onset shows injury on the left dorsolateral prefrontal cortex, corona radiate, basal ganglia and internal capsule due to infarction of left posterior cerebral artery. (B) Diffusion tensor imaging of the corticospinal tract and corticoreticular pathway in the affected hemisphere showed intact integrity like the unaffected hemisphere. 
tional ambulation category) 척도는 4점(계단 보행에 있어 감독이 필요 한상태)이었다. ${ }^{19}$

\section{2. 확산 텐서 영상(diffusion tensor image)}

DTI 데이터는 $1.5 \mathrm{~T}$ 자기공명영상장치(Philips Gyroscan Intera system, BEST, Netherlands)와 single-shot echo-planar imaging에 대한 6개 채널 의 두부 코일을 장착하여 뇌졸중 후 4 주 후에 측정되었다. 각각의 32 개의 비공선적 확산 증감 경사에 대해, 전측 교련(anterior commissure) 연결선에 평행하게 67 개의 인접하는 절편 영상들이 획득되었다. 취득된 영상 매개 변수는 다음과 같다: 획득 매트릭스 $=96 \times 96$, 재구 성된 매트릭스 $=192 \times 192$, 영상범위 $=240 \times 240 \mathrm{~mm}^{2}$, 반복시간 $=10,726 \mathrm{~ms}$, 에코시간 $=76 \mathrm{~ms}$, 병렬 영상 축소 인자 $=2$, 에코 평면 영 상 인자 $=49, \mathrm{~b}=1,000 \mathrm{~s} / \mathrm{mm}^{2}$, 자극 회수 $=1$, 슬라이스 두께: 갭 없이 $2.5 \mathrm{~mm}$ (취득 된 복셀 크기 $1.3 \times 1.3 \times 2.5 \mathrm{~mm}^{3}$ ).

\section{3. 확률적 섬유 추적(probabilistic fiber tracking)}

확산텐서영상 데이터는 Oxford centre for functional magnetic resonance imaging of the brain (FMRIB) software library (FSL; www.fmrib. ox.ac.uk/fsl)를 사용하여 분석되었다. 와전류로 인해 머리 움직임 영 향과 영상 왜곡의 상관관계를 위해 affine multi-scale two-dimensional registration이 사용되었다. 운동신경섬유의 분석은 다중 광파 모델을 기반으로 한 확률적 신경다발영상(tractography) 방법을 이용하여 수 행되었으며, FMRIB 확산(5,000개의 유선형 샘플, $0.5 \mathrm{~mm}$ 스텝 길이, 곡률 임계 값 $=0.2)$ 에서 구현된 신경다발영상 루틴을 사용하여 본 연 구에 적용하였다.

각 운동신경경로는 다음과 같이 seed와 target region of interest (ROI) 를 통과하는 섬유에 의해 결정되었다; 겉질척수로: seed ROI- 컬 러맵에서 연수 교뇌 이행부(pontomedullary junction)의 겉질척수로 부분, target ROI 1- 앞쪽 중간 다리뇌의 겉질척수로 부분, target ROI 2일차 운동 겉질, ${ }^{20}$ 겉질그물체로: seed ROI- 숨뇌의 그물체, target ROI 1 - 중간뇌 덮개, target ROI 2 - 앞운동겉질. ${ }^{21}$

\section{4. 보행 측정(gait measurement)}

보행에 대한 운동학적 및 시공간적 변수들은 LEGSys+ 장치(BioSensics, Cambridge, Massachusetts, USA)를 사용하여 측정되었다. 5 개의 착용식 센서들 $(5.0 \mathrm{~cm} \times 4.2 \mathrm{~cm} \times 1.2 \mathrm{~cm})$ 은 블루투스로 컴퓨터에 연결 되었으며 세 개의 축으로 자이로스콥, 가속도계 및 자력계가 포함되 어있다. $22-24$ 각 센서는 벨크로 스트랩으로 양쪽 발목 위 $3 \mathrm{~cm}$ 정강이, 무릎 위 $3 \mathrm{~cm}$ 허벅지 앞쪽 면 및 위뒤엉덩뼈가시(posterior superior iliac spine, PSIS) 중앙에 부착되었다. 본 연구에서 사용된 sampling 주파 수는 $100 \mathrm{~Hz}$ 로 설정하였다. 대상자들은 5 개 이상의 stride가 되도록 $7 \mathrm{~m}$ 거리를 걷도록 지시받았다. 본 실험은 보행 과제를 실시할 때 각 걸음 에서 발생하는 특성들을 기록하였다. 본 연구는 첫 번째와 마지막 걸 음을 제외하고 중간 3 개 걸음의 운동학적 데이터와 시공간적 데이터 를 기록하였다. 본 연구는 보행 동안 무릎과 엉덩관절에 대한 관절각 도범위와 걸음 거리, 걸음 속도, 한 발짝 거리 및 분속수를 측정하였 다. 본 연구에서는 정상 대조군 평균값을 기준으로 두 배 이상의 표 준편차를 보이는 보행 변수들은 유의한 차이가 있는 것으로 정의하 였다 (reference range $=$ mean $\pm 2 \mathrm{SD})$.

\section{결 과}

확산텐서영상 분석결과 일차운동영역에서 시작하여 대뇌부챗살, 속 섬유막, 중뇌와 숨뇌를 거쳐 척수로 이어지는 겉질척수로는 손상측 반 구와 비손상측 반구 모두에서 특별한 손상이 없는 것으로 관찰되었 다(Figure 1B). 또한, 전운동영역에서 시작하여 속섬유막과 뇌줄기의 망상체로 연결되는 겉질그물체로의 경우에도 손상측 반구와 비손상 측 반구 모두에서 특별한 손상이 없는 것으로 관찰되었다(Figure 1B).

뇌졸중 환자와 정상 대조군의 보행분석결과, 시공간적 변수에서 는 뇌졸중 환자의 분속수에서 유의한 감소 양상을 보였다(Table 1). 반면 한 발짝 거리와 보폭의 경우 환자의 대조군에서 유의한 차이를 보이지 않았다. 운동학적 변수에 대한 분석결과, 뇌졸중 환자의 비마 비측과 마비측 무릎 모두에서 대조군과 비교하여 유의한 관절 움직 임 감소 양상이 관찰되었다. 반면에 엉덩관절의 관절움직임은 두 그 룹간 유의한차이를 보이지 않았다(Figure 2).

Table 1. Spatio-temporal and kinematic parameters during gait in a patient and control subjects.

\begin{tabular}{|c|c|c|c|c|c|c|c|c|}
\hline & \multicolumn{4}{|c|}{ Spatio-temporal parameters } & \multicolumn{4}{|c|}{ Kinematic parameters } \\
\hline & \multicolumn{2}{|c|}{ Step Length $(\mathrm{m})$} & \multirow{2}{*}{ Stride length (m) } & \multirow{2}{*}{ Cadence } & \multicolumn{2}{|c|}{ Knee joint (deg) } & \multicolumn{2}{|c|}{ Hip joint (deg) } \\
\hline & Left (unaff) & Right (aff) & & & Left (unaff) & Right (aff) & Left (unaff) & Right (aff) \\
\hline Patient & 0.42 & 0.64 & 1.06 & $92.11^{*}$ & $45.53^{*}$ & $30.66^{*}$ & 45.57 & 40.38 \\
\hline Controls & $0.63(0.12)$ & $0.65(0.05)$ & $1.28(0.12)$ & $117.42(6.11)$ & $59.54(5.38)$ & $57.49(3.11)$ & $48.98(5.41)$ & $47.25(5.64)$ \\
\hline Reference ranges & $0.85-0.39$ & $0.74-0.55$ & $1.51-1.04$ & $129.63-105.21$ & $70.31-48.78$ & $63.72-51.26$ & $59.80-38.16$ & $58.53-35.98$ \\
\hline
\end{tabular}



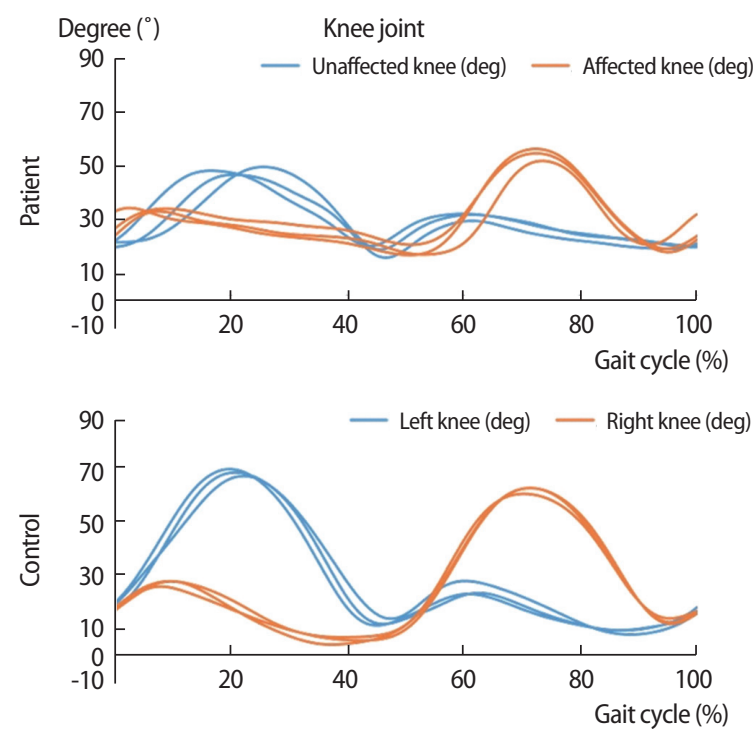
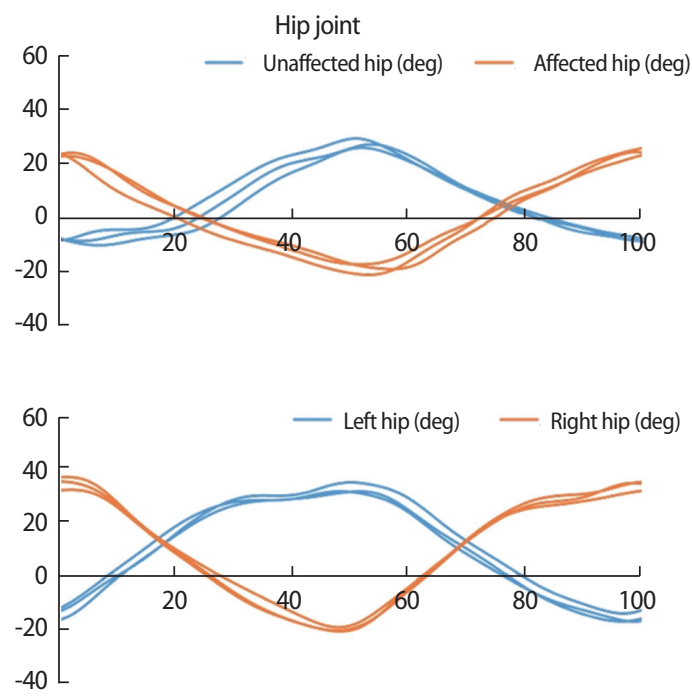

Figure 2. Three-dimensional gait analysis; joint kinematic in the sagittal plane of hip and knee joint in a patient and a control subject (63-year-old male).

고 찰

본 연구에서는 왼쪽 아래대뇌동맥(inferior cerebral artery) 폐색으로 뇌졸중 진단을 받은 환자를 대상으로 하여 겉질척수로와 겉질그물 체로의 손상유무를 평가하였고, 그에 따른 독립보행 양상을 동작분 석 시스템을 사용하여 평가하였다. 확산텐서영상 평가 결과, 손상측 과 비손상측 반구의 겉질척수로와 겉질그물체로에 특별한 손상은 없 는 것으로 나타났다. 또한 환자는 $\mathrm{FAC}$ 점수 4점으로 계단을 제외한 평지 보행은 독립적으로 가능한 상태였다. 그러나 3 차원 보행분석결 과, 분속수가 동일 연령대의 정상성인에 비하여 감소한 것으로 나타 났으며, 마비측과 비마측 하지의 무릎관절 움직임 범위도 유의하게 감소한 것으로 나타났다. 결과적으로, 본 연구에서는 아래대뇌동맥 경색으로 인해 겉질과 겉질 밑 영역에 손상이 발생하더라도 겉질척 수로와 겉질그물체로에 손상이 없을 수 있음을 확인하였다. 또한 정 상적인 운동 신경로의 연결성을 유지한 뇌졸중 환자의 경우 평지에 서의 독립 보행이 충분히 가능하다는 것을 확인하였다. 하지만, 뇌졸 중 후 확산텐서영상 평가에서 운동신경로에 정상소견을 보인다 하더 라도, 정량적인 보행분석에서는 정상성인에 비하여 보행의 수준이나 질이 떨어질 수 있을 것이다.

다양한 연구들에서 뇌졸중에 따른 겉질척수로와 겉질그물체로의 손상이 발생한 환자의 경우에도 독립적인 보행이 가능하다는 것으 로 보고하였다. ${ }^{7,25,26} \mathrm{Ahn}$ 등 25 은 10 명의 뇌졸중 환자를 대상으로 하여 겉질척수로에 완전 손상이 있는 경우에도 평균 FAC 3.5점으로 독립 보행기능의 회복이 가능하다는 것을 보고하였다. 또한, Jang 등근 뇌 졸중 발병 후 겉질척수로와 겉질그물체로에 완전 손상이 있는 환자 들 중 $63 \%$ 정도에서 독립 보행기능의 회복이 가능하다는 것을 보고
하였다. 하지만, 이러한 연구결과들은 운동신경로의 손상 정도에 따 른 보행기능이 수준을 정량적이고 객관적인 평가가 이루어지지 않았 으며, 독립보행의 수준을 수치화하기에 어려운 점이 있다. 최근에는 확산텐서영상과 보행분석시스템을 융합하여 뇌졸중 환자에게서 운 동신경로의 손상 정도에 따른 보행기능을 정량적으로 분석한 연구 가 보고되었다. Seo 등 26 은 확산텐서영상에서 겉질척수로에 심각한 손상을 입은 뇌졸중 환자의 경우 발목관절의 발등 굽힘과 무릎관절 의 안쪽돌림 그리고 엉덩관절의 굽힘동작에서 유의하게 감소되었다 고 보고하였다. 하지만 겉질척수로와 겉질그물체로의 손상 양상에 따른 보행 특성의 변화는 잘 알려져 있지 않으며, 뇌졸중 환자의 내측 및 외측 전정척수로와 보행 회복 간의 관련성에 대한 연구 또한 많지 않다.

결론적으로 본 연구에서는 아래대뇌동맥 경색 환자에서 겉질척수 로와 겉질그물체로 손상 양상에 따른 보행 특성의 변화를 보고하였 다. 연구결과를 종합하여 볼 때 확산텐서영상의 분석결과 겉질척수 로와 겉질그물체로에 정상적인 소견과 서열척도를 통해 독립적인 보 행이 가능하다고 평가된 환자의 경우에도 정량적이고 객관적인 보행 분석을 시행한 경우 보행의 질이나 양이 감소된 결과가 나올 수 있을 것으로 사료된다. 본 연구의 결과는 뇌졸중 환자의 보행 능력 분석과 뇌 손상 환자의 비정상적인 보행 패턴에 대한 이해에 도움이 될 수 있 을 것으로 생각된다. 그러나 본 연구는 증례 보고이므로 연구의 결과 를 일반화할 수 없다는 제한점을 가지고 있다. 또한, ROI의 설정이 분 석자에 의해 달라질 수 있으며, 교차섬유로 인해 운동신경로의 완벽 한 분석이 어려웠을 수 있다. 따라서 연구의 결과를 보완하고 일반화 하기 위해서 보다 많은 사례를 추가한 후속 연구가 필요할 것으로 사 료된다. 


\section{ACKNOWLEDGEMENTS}

This research was supported by Basic Science Research Program through the National Research Foundation of Korea (NRF), funded by the Ministry of Education, Science and Technology (NRF-2015R1D1A1A01060314).

\section{참고문헌}

1. Fukuyama H, Ouchi Y, Matsuzaki S et al. Brain functional activity during gait in normal subjects: a SPECT study. Neurosci Lett. 1997;228(3):1836.

2. Gagnon I, Swaine B, Friedman D et al. Children show decreased dynamic balance after mild traumatic brain injury. Arch Phys Med Rehabil. 2004;85(3):444-52.

3. Drew T, Prentice S, Schepens B. Cortical and brainstem control of locomotion. Prog Brain Res. 2004;143:251-61.

4. Takakusaki K. Neurophysiology of gait: from the spinal cord to the frontal lobe. Mov Disord. 2013;28(11):1483-91.

5. Jahn K, Deutschlander A, Stephan T et al. Brain activation patterns during imagined stance and locomotion in functional magnetic resonance imaging. Neuroimage. 2004;22(4):1722-31.

6. Jones PS, Pomeroy VM, Wang J et al. Does stroke location predict walk speed response to gait rehabilitation? Hum Brain Mapp. 2016;37(2):689703.

7. Jang SH, Chang $\mathrm{CH}$, Lee J et al. Functional role of the corticoreticular pathway in chronic stroke patients. Stroke. 2013;44(4):1099-104.

8. You SH, Jang SH, Kim YH et al. Virtual reality-induced cortical reorganization and associated locomotor recovery in chronic stroke: an experimenter-blind randomized study. Stroke. 2005;36(6):1166-71.

9. Regnaux JP, Pradon D, Roche N et al. Effects of loading the unaffected limb for one session of locomotor training on laboratory measures of gait in stroke. Clin Biomech. 2008;23(6):762-8.

10. Rosano C, Aizenstein H, Brach J et al. Special article: gait measures indicate underlying focal gray matter atrophy in the brain of older adults. J Gerontol A Biol Sci Med Sci. 2008;63(12):1380-8.

11. Tononi G, McIntosh AR, Russell DP et al. Functional clustering: identifying strongly interactive brain regions in neuroimaging data. Neuroimage. 1998;7(2):133-49.

12. Hara Y. Brain plasticity and rehabilitation in stroke patients. J Nippon Med Sch. 2015;82(1):4-13.
13. Agosta F, Gatti R, Sarasso E et al. Brain plasticity in Parkinson's disease with freezing of gait induced by action observation training. J Neurol. 2017;264(1):88-101.

14. Tan Z, Liu H, Yan T et al. The effectiveness of functional electrical stimulation based on a normal gait pattern on subjects with early stroke: a randomized controlled trial. Biomed Res Int. 2014;2014:545408.

15. Fernandez-Lago H, Bello O, Lopez-Alonso V et al. Gait pattern and cognitive performance during treadmill walking in Parkinson disease. Am J Phys Med Rehabil. 2015;94(11):931-40.

16. Kraan CM, Tan AHJ, Cornish KM. The developmental dynamics of gait maturation with a focus on spatiotemporal measures. Gait Posture. 2017;51:208-17.

17. Ong A, Harris IS, Hamill J. The efficacy of a video-based marker-less tracking system for gait analysis. Comput Methods Biomech Biomed Engin. 2017;20(10):1089-95.

18. Kuhtz-Buschbeck JP, Hoppe B, Golge M et al. Sensorimotor recovery in children after traumatic brain injury: analyses of gait, gross motor, and fine motor skills. Dev Med Child Neurol. 2003;45(12):821-8.

19. Cunha IT, Lim PA, Henson $H$ et al. Performance-based gait tests for acute stroke patients. Am J Phys Med Rehabil. 2002;81(11):848-56.

20. Jang SH. Somatotopic arrangement and location of the corticospinal tract in the brainstem of the human brain. Yonsei Med J. 2011;52(4):5537.

21. Yeo SS, Chang MC, Kwon YH et al. Corticoreticular pathway in the human brain: diffusion tensor tractography study. Neurosci Lett. 2012; 508(1):9-12.

22. Gill SV, Walsh MK, Pratt JA et al. Changes in spatiotemporal gait patterns during flat ground walking and obstacle crossing 1 year after bariatric surgery. Surg Obes Relat Dis. 2016;12(5):1080-5.

23. Najafi B, Helbostad JL, Moe-Nilssen R et al. Does walking strategy in older people change as a function of walking distance? Gait Posture. 2009;29(2):261-6.

24. Zukowski LA, Martin JM, Scronce G et al. The influence of cognitive load on metabolic cost of transport during overground walking in healthy, young adults. Eur J Appl Physiol. 2017;117(4):679-86.

25. Ahn YH, Ahn SH, Kim H et al. Can stroke patients walk after complete lateral corticospinal tract injury of the affected hemisphere? Neuroreport. 2006;17(10):987-90.

26. Seo JP, Do KH, Jung GS et al. The difference of gait pattern according to the state of the corticospinal tract in chronic hemiparetic stroke patients. NeuroRehabilitation. 2014;34(2):259-66. 